\title{
INFERENCES FROM A COMMUNITY STUDY ABOUT NON-EPILEPTIC EVENTS
}

\author{
Marleide da Mota Gomes', Leandro Albuquerque Lemgruber Kropf², \\ Erica da Silva van Beeck², Ivan Luiz de Vasconcellos Figueira ${ }^{3}$
}

\begin{abstract}
Objective: To demonstrate the epidemiological importance of the different types of non-epileptic events (NEE) in a low-income urban community. Method: The patients suspected of having epilepsy, who were detected in the first phase (screening one) of this prevalence study, were interviewed by a neurologist in a non-structured neurological interview. These NEE were classified as physiological and psychogenic, subdivided by various types. The psychogenic NEE were classified according to the DSM-IV criteria. Results: We compared the cases suspected of having epilepsy $(n=176)$ with those not suspected $(n=806)$ and discovered that those cases suspected of having epilepsy had a greater median age $(<0.01)$ and female predominance $(p<0.01)$. Among the cases suspected of having epilepsy there were different diagnosis: epileptic events without identifiable cause $(n=20)$ or with identifiable causes (e.g., febrile convulsions and eclampsia). The most prevalent diagnosis for those suspected of having epilepsy was syncope $(n=63 ; 35.8 \%)$. In terms of physiological events, the most frequent were: epileptic seizures, paroxysmal toxic phenomena (including alcoholism) and brain trauma, besides syncope; in terms of psychogenic events the most frequent were: dissociative and anxiety disorders. Regarding gender differences, paroxysmal toxic problems were significantly more prevalent in men $(p=0.02)$, and dissociative disorders $(p=0.01)$ in women. Conclusion: This survey confirms the epidemiological importance of syncope in a populational sample with NEE. However, among the psychogenic disorders of this NEE sample, the most frequent were dissociative and anxiety phenomena. This finding contrasts with the literature based on samples from tertiary epileptic centers with video-EEG resources, which found somatoform disorders to be more prevalent than dissociative and anxiety phenomena.
\end{abstract}

KEY WORDS: epilepsy, non-epileptic events, community study.

Inferências de estudo populacional sobre eventos não epilépticos

RESUMO - Objetivo: Demonstrar a importância epidemiológica dos diferentes tipos de eventos não epilépticos (ENE) em uma comunidade urbana de baixa renda. Metodo: Os casos suspeitos de terem epilepsia foram detectados na primeira fase de um estudo de prevalência de epilepsia, de triagem. Na segunda fase, eles foram entrevistados por um neurologista em entrevista não estruturada. Os casos de ENE foram classificados como fisiológicos ou psicogênicos e divididos em vários tipos. Esses últimos foram classificados segundo o DSM-IV. Resultados: Entre os suspeitos de terem epilepsia (176, mais idosos do que os outros casos, $<0.01$, com predominância feminina, $\mathrm{p}<0.01)$ existem diferentes diagnósticos: eventos epilépticos sem causa aguda subjacente conhecida (20) ou com (convulsão febril e eclâmpsia). O diagnóstico mais prevalente é o de síncope $(n=63 ; 35,8 \%)$, crises epilépticas, fenômeno tóxico paroxístico (incluso alcoolismo) e trauma craniano, nos eventos fisiológicos, e transtornos dissociativos, ansiedade, entre os psicogênicos. 0 predomínio masculino está relacionado aos fenômenos tóxicos $(p=0,02)$, e o feminino, aos fenômenos dissociativos $(p=0,01)$. Conclusão: Dentre os ENE, sugere-se a importância populacional (epidemiológica) da síncope, como já enfatizado na literatura médica, e, dentre os transtornos psicogênicos, fenômenos de ansiedade e dissociativos mais do que transtornos somatoformes, usualmente mais investigados em centros terciários de epilepsia com recursos de video-EEG.

PALAVRAS-CHAVE: epilepsia, eventos não epilépticos, estudo populacional.

The distinction between epileptic and non-epileptic events (NEE) is clinically important and is based mainly on clinical histories and auxiliary tests (e.g., imaging and neurophysiological). The medical literature emphasizes the epidemiological importance of both convulsive psychogenic NEE cases, and the

Programa de Epilepsia, Programa de Epidemiologia Clínica da Faculdade de Medicina (FM) Hospital Universitário / Universidade Federal do Rio de Janeiro (UFRF) Rio de Janeiro RJ, Brasil: ${ }^{1}$ Associated Professor, Neurologist, FM/UFRJ; ${ }^{2}$ Student of Medicine, FM-UFRJ; ${ }^{3}$ Associated Professor, Psychiatrist, FM/UFRJ. Support: This work was partially supported by Conselho Nacional de Pesquisa-CNPq and Fundação José Bonifácio FUJB/UFRJ.

Received 1 February 2002. Accepted 23 April 2002.

Dra. Marleide da Mota Gomes - Caixa Postal 68008 - Centro de Ciências da Saúde, Bloco K - Cidade Universitária, Ilha do Fundão - Av. Brigadeiro Trompowski, s/no - 21941-590 Rio de Janeiro RJ - Brasil. 
usually chronic, severe and selected cases from epilepsy medical centers. Gates et al, 1991 apud Gates', estimated that the prevalence of NEE ranged from 5 to $20 \%$ in an outpatient epileptic population, but may be even higher (10 to 40\%) in inpatient epilepsy centers. Krumholz ${ }^{2}$, found NEE in $20 \%$ of all intractable seizure disorders referred to a comprehensive epilepsy center.

Despite these studies indicating a high prevalence of NEE, to the best of our knowledge, there is no epidemiological research about NEE in community samples. In a review of the Medline database, we found only one study related to the NEE concept; this 1998 study, by Sigurdardottir and Olafsson ${ }^{3}$, examined the incidence of psychogenic seizures in adults in Iceland. Consequently, there is a shortage of studies in community samples.

The present article is based on an epilepsy prevalence study that determined the frequency of epilepsy disorder and epileptic seizures in a community sample ${ }^{4}$. A secondary analysis of these data was then performed to determine the distribution of cases suspected of having NEE or epileptic seizures (acute symptomatic or not).

\section{METHOD}

This is a prevalence study based on a two-phase design: the first phase was a screening field study; the second phase was a neurological examination designed to assess the prevalence of epilepsy in a community sample of 906 people (More information about this study's methodology is presented in another paper ${ }^{4}$ ). In the second phase, a senior neurologist interviewed the subjects with a positive screening questionnaire for epilepsy. This questionnaire, designed by Placencia et al. ${ }^{5}$, was translated to the Portuguese and pretested for our study. Those participants who tested positive according to the questionnaire were then examined in a non-structured neurological interview (which included relatives or witnesses of the seizures). After review of the case records, the neurologist classified them for NEE. These NEE cases were then further classified either as physiological (brain trauma, breath hold spell, cerebrovascular disorders, movement disorders, paroxystical toxic phenomena, sleep disorders, syncope / vertigo and migraine) or psychogenic (anxiety disorders, attention deficit disorder, disorders with psychotic symptoms, dissociative disorders, somatoform disorder). The classification of psychogenic events was based on the DSM-IV ${ }^{6}$ and reviewed by two psychiatrists.

A descriptive analysis of data regarding age, gender, and items of the screening questionnaire was performed,

Table 1. Age and gender distribution of the suspected cases $(N=176)$.

\begin{tabular}{|c|c|c|c|c|c|c|}
\hline \multirow{3}{*}{$\frac{\text { Means }(\mathrm{SD})^{*}}{\text { Age Years }}$} & \multicolumn{2}{|c|}{ Men } & \multicolumn{2}{|c|}{ Women } & \multicolumn{2}{|c|}{ Total } \\
\hline & \multicolumn{2}{|c|}{$36.6(21.3)$} & \multicolumn{2}{|c|}{$37.2(20.0)$} & \multicolumn{2}{|c|}{$37.0(19.8)$} \\
\hline & $\mathrm{n}$ & $\%$ & $\mathrm{n}$ & $\%$ & $\mathrm{n}$ & $\%$ \\
\hline $0-9$ & 6 & 9.8 & 5 & 4.3 & 11 & 6.3 \\
\hline $10-19$ & 11 & 8.0 & 21 & 18.3 & 32 & 18.2 \\
\hline $20-29$ & 7 & 11.5 & 21 & 18.3 & 28 & 15.9 \\
\hline $30-39$ & 13 & 21.3 & 26 & 22.6 & 39 & 22.2 \\
\hline $40-49$ & 7 & 11.5 & 13 & 11.3 & 20 & 11.4 \\
\hline $50-59$ & 5 & 8.2 & 11 & 9.6 & 16 & 9.1 \\
\hline $60-69$ & 7 & 11.5 & 11 & 9.6 & 18 & 10.2 \\
\hline $70-98$ & 5 & 8.2 & 7 & 6.1 & 12 & 6.9 \\
\hline Total & 61 & 100 & 115 & 100 & 176 & 100 \\
\hline
\end{tabular}

Table 2. Age and gender distribution of non-suspected cases $(N=806)$ and the suspected cases $(N=176)$.

\begin{tabular}{|c|c|c|c|c|c|}
\hline & \multicolumn{2}{|c|}{ Men } & \multirow{2}{*}{$\begin{array}{c}\mathrm{p} \text { value } \\
<0.01\end{array}$} & \multicolumn{2}{|c|}{ Women } \\
\hline & $\begin{array}{l}\text { Non-suspected } \\
\qquad(\mathrm{N}=387)\end{array}$ & $\begin{array}{l}\text { Suspected } \\
\qquad(\mathrm{N}=61)\end{array}$ & & $\begin{array}{l}\text { Non-suspected } \\
\quad(\mathrm{N}=419)\end{array}$ & $\begin{array}{c}\text { Suspected } \\
(N=115)\end{array}$ \\
\hline Means (SD)* & $26.8(18.9)$ & $36.6(21.3)$ & & $30.0(20.1)$ & $37.2(20.0)$ \\
\hline
\end{tabular}


Table 3. Diagnosis of the suspected cases $(N=176)$.

\begin{tabular}{|c|c|c|c|c|c|c|c|}
\hline \multirow[b]{2}{*}{ Diagnosis } & \multicolumn{2}{|c|}{ Men } & \multicolumn{2}{|c|}{ Women } & \multicolumn{3}{|c|}{ Total } \\
\hline & $\mathrm{n}$ & $\%$ & $\mathrm{n}$ & $\%$ & $\mathrm{p}$ & $\mathrm{n}$ & $\%$ \\
\hline Syncope & 19 & 31.1 & 44 & 38.3 & 0.44 & 63 & 35.8 \\
\hline Epileptic seizures & 10 & 16.4 & 10 & 8.7 & 0.28 & 20 & 11.4 \\
\hline Paroxystical toxic phenomena & 8 & 13.1 & 3 & 2.6 & 0.02 & 11 & 6.3 \\
\hline Dissociative disorders & 0 & 0 & 10 & 8.7 & 0.01 & 10 & 5.7 \\
\hline Anxiety disorders & 1 & 1.6 & 9 & 7.8 & 0.08 & 10 & 5.7 \\
\hline Brain trauma & 6 & 9.8 & 4 & 3.5 & 0.08 & 10 & 5.7 \\
\hline Movement disorders & 3 & 4.9 & 9 & 7.8 & 0.2 & 12 & 6.8 \\
\hline Vertigo & 0 & 0 & 5 & 4.8 & 0.11 & 5 & 2.8 \\
\hline Cerebrovascular disorders & 3 & 4.9 & 3 & 2.6 & 0.34 & 6 & 3.4 \\
\hline Attention deficit & 2 & 3.3 & 2 & 1.7 & 0.43 & 4 & 2.5 \\
\hline Febrile convulsion & 2 & 3.3 & 2 & 1.7 & 0.43 & 4 & 2.3 \\
\hline Sleep disorders & 1 & 1.6 & 2 & 1.7 & 0.72 & 3 & 1.7 \\
\hline Migraine & 1 & 1.6 & 2 & 1.9 & 0.72 & 3 & 1.7 \\
\hline Breath hold spell & 1 & 1.6 & 1 & 0.9 & 0.57 & 2 & 1.1 \\
\hline Disorders with psychotic symptoms & 1 & 1.6 & 1 & 0.9 & 0.57 & 2 & 1.1 \\
\hline Eclampsia & 0 & 0 & 1 & 0.9 & 0.65 & 1 & 0.6 \\
\hline Somatoform disorder & 0 & 0 & 2 & 1.7 & 0.42 & 2 & 1.1 \\
\hline Lost & 3 & 4.9 & 5 & 4.8 & 0.63 & 8 & 4.5 \\
\hline Total & 61 & 100 & 115 & 100 & - & 176 & 100 \\
\hline
\end{tabular}

as well as analytical analyses for defining significant differences (Student $t$ test for numerical data and $\mathrm{X}^{2}$ tests (Yates corrected or Fisher test) for categorical variables). The statistical package Epi Info 6.01 was used. The proportion estimation precision was calculated by the exact binomial 95\% confidence interval.

\section{RESULTS}

The basic characteristics of the studied population are presented on Table 1. The NEE suspected cases were older than the other cases, and there is a female predominance (Table 2). Among the suspected cases there were different diagnosis: epileptic events without acute subjacent cause $(n=20)$ or with obvious subjacent cause (e.g., febrile convulsions and eclampsia). The others were cases of different NEE including those related to alcoholism classified as paroxysmal toxic phenomena. For the physiological events, the most prevalent diagnosis include syncope, epileptic seizures, paroxysmal toxic phenomena and brain trauma (Table 3). For the psychogenic events, the most prevalent diagnosis were dissociative disorders and anxiety disorders (Table 3 ). The male predominance was related to the paroxysmal toxic phenomena, and the female, to the dissociative as presented in Table 3. Table 4 presents the proportion of those who responded positively to each question of the screening questionnaire. Loss of consciousness was the most important question answered positively both in the cases of epileptic seizures and syncope (sensitivity of $75 \%$ and specificity of $45 \%$ for epileptic seizures). The most specific question to epileptic seizure is linked to the question 9 (sensitiviy of $40 \%$ and specificity of $97 \%$ ).

\section{DISCUSSION}

To our knowledge this is the first published article trying to define the epidemiological profile of different NEE in the general population. However, the events reported had sometimes only occurred once or had happened years before. They were thus prone 
Table 4. Evaluation by single items of the screening test related to the suspected cases.

\begin{tabular}{|c|c|c|c|c|c|c|c|c|c|}
\hline \multirow[b]{2}{*}{ Diagnosis } & \multicolumn{9}{|c|}{ Questions } \\
\hline & Q1 & Q2 & Q3 & Q4 & Q5 & Q6 & Q7 & Q8 & Q9 \\
\hline Epileptic Seizures & 12 & 12 & 15 & 12 & 7 & 5 & 14 & 9 & 8 \\
\hline Anxiety Disorders & 8 & 5 & 3 & 2 & 2 & 1 & 6 & 3 & 2 \\
\hline Attention Deficit & 0 & 0 & 1 & 0 & 0 & 0 & 0 & 3 & 0 \\
\hline Brain Trauma & 1 & 1 & 7 & 6 & 1 & 0 & 0 & 0 & 0 \\
\hline Breath Hold Spell & 0 & 0 & 0 & 0 & 0 & 1 & 0 & 1 & 0 \\
\hline Cerebrovascular Disorders & 3 & 1 & 1 & 1 & 0 & 0 & 5 & 0 & 0 \\
\hline Disorders With Psychotic Symptoms & 1 & 1 & 1 & 0 & 0 & 0 & 1 & 1 & 0 \\
\hline Dissociative Disorders & 0 & 0 & 2 & 0 & 0 & 0 & 1 & 8 & 0 \\
\hline Eclampsia & 0 & 0 & 1 & 1 & 0 & 0 & 1 & 1 & 0 \\
\hline Febrile Convulsion & 3 & 2 & 1 & 0 & 0 & 0 & 3 & 0 & 1 \\
\hline Movement Disorders & 4 & 2 & 1 & 1 & 0 & 0 & 12 & 1 & 0 \\
\hline Paroxystical Toxic Phenomena1 & 3 & 2 & 8 & 3 & 0 & 1 & 4 & 2 & 0 \\
\hline Sleep Disorders & 0 & 0 & 1 & 0 & 0 & 0 & 1 & 1 & 0 \\
\hline Somatoform Disorder & 2 & 1 & 0 & 0 & 1 & 0 & 1 & 1 & 0 \\
\hline Syncope & 12 & 28 & 50 & 28 & 1 & 2 & 19 & 12 & 0 \\
\hline Vertigo & 1 & 4 & 2 & 1 & 0 & 0 & 0 & 3 & 0 \\
\hline Migraine & 1 & 0 & 1 & 0 & 0 & 0 & 2 & 2 & 0 \\
\hline Lost & 2 & 3 & 6 & 3 & 1 & 0 & 2 & 2 & 0 \\
\hline Total & 53 & 62 & 101 & 58 & 13 & 10 & 72 & 50 & 11 \\
\hline
\end{tabular}

Q1., Have you ever had attacks of shaking of the arms or legs which you could not control?; Q2., Have you ever had attacks, in which you fall and become pale?; Q3., Have you ever lost consciousness?; Q4., Have you ever had attacks in which you fall with loss of consciousness?; Q5., Have you ever had attacks, in which you fall and bite your tongue?; Q6.,Have you ever had attacks, in which you fall and lose control of your bladder?; Q7.,Have you ever had brief attacks of shaking or trembling in one arm or leg or in the face?; Q8., Have you ever had attacks in which you lose contact with the surroundings and experience abnormal smells/sensations?; Q9., Have you ever been told that you have had epilepsy or epileptic fits? (by Placencia et al. $^{5}$ )

to misinterpretation. The majority of these events were not of long term duration, but evanescent. Regarding the psychogenic diagnosis, at maximum the majority would be classified as "without other specification" according to DSM-IV. The predominance of syncope is already attested to by the medical literature ${ }^{7}$. The incidences of confusional migraine and vertebrobasilar migraine $^{8}$ have to be differentiated from the epileptic events, because of the very high prevalence of migraine in the population (mainly in women) and the possibility of alterations in the EEG. Breath hold spells are another common occurence in children?.

Among the psychogenic NEE, anxiety and dissociative disorders predominate. This contradicts extant research; however, this kind of research has usually focused on the difficult cases of non-epileptic convulsive events, such as the 1998 community study of Sigurdardottir \& Olafsson, in Iceland ${ }^{3}$. The 1994 epidemiological study by Kessler et al. ${ }^{10}$ about psychiatric disorders in the United States, confirms the high prevalence of affective and anxiety disorders among women, and substance use disorders among men. Kessler's research confirms this paper's findings of high rates of anxiety disorders in women and toxic phenomena in men ${ }^{10}$.

Additionally, we considered as relevant cases of derealization, similar to dejá vu or jamais vu phenomena, which are more common in non-epileptic than epileptic events. However, we did not always find clearly-expressed psychogenic stressor factors that 
would justify the psychogenic diagnosis (neither organic, nor related to delirium). We conclude that the distinction and recognition of the epidemiological profile of clinical phenomena that resemble epilepsy is of practical clinical value. This recognition would help the final diagnosis based on diagnostic probability. It is important that the relative magnitude of the NEE at the community level, from mild to severe cases, be recognized in order to avoid misinterpretation and unnecessary antiepileptic drug use and stigma. We expect that it would be possible to propose a methodologically adequate study of the clinical profile of NEE in the whole community based on this preliminary study.

Acknowledgments - We thank the team coordinated by Regina Zeitoune Gollner, Associate Professor of the Nurse Faculty of UFRJ, participant in the prevalence study of epilepsy, for their help in allowing us to analyze more thoroughly the suspected cases. Thanks are also due to Dr.Adriana Fiszman for her help in the study of the psychiatric diagnosis.

\section{REFERENCES}

1. Gates JR. Epidemiology and classification of non-epileptic events. In Gates JR, Rowan AJ (eds), Non-epileptic events. Boston: Butterworth / Heinemann, 2000:3-14

2. Krumholz A. Nonepileptic seizures: diagnosis and management. Neurology 1999; 53(Supp 2):76-83.

3. Sigurdardottir KR, Olafsson E. Incidence of psychogenic seizures in adults: a population-based study in Iceland. Epilepsia 1998;39:857-862.

4. Gomes MM, Zeitoune RG, Kropf LAL, van Beeck ES. A house-to-house survey of epileptic seizures in a urban community of Rio de JaneiroBrazil. Arq Neuropisiquiatr 2002;60:708-711

5. Placencia M, Suarez J, Crespo F, et al. A large scale study of epilepsy in Ecuador: methodological aspects. Neuroepidemiology 1992;11:74-84.

6. DSM-4. Manual diagnóstico e estatístico de transtornos mentais. Trad Dayse Batista. 4.Ed. Porto Alegre: Artes Médicas, 1995.

7. Smith PEM. If it's not epilepsy. J Neurol Neurosurg Psychiatry 2001;70(Supp 2):9-14.

8. Geraud G. Rare and atypical forms of migraine. Rev Neurol 2000;156(Supp 4):42-46.

9. Ritter FJ, Kotagal P. Non-epileptic seizures in children. In Gates JR, Rowan AJ (eds), Non-epileptic events. Boston: Butterworth / Heinemann, 2000:95-110.

10. Kessler RC, McGonagle KA, Zhao S, et al. Lifetime and 12-month prevalence of DSM-III-R psychiatric disorders in the United States: results from the national comorbidity survey. Arch Gen Psychiatry 1994;51:8-19. 